\title{
Risk factors associated with surveillance loss after endoscopic submucosal dissection in patients with gastric neoplasm
}

\author{
Manwoo Lee ${ }^{1 \#}$, Kyungchul Kim ${ }^{1 \#}$, Yong Kang Lee ${ }^{1}$, Byung Kyu Park ${ }^{1}$, San Lee ${ }^{2,3}$, Han Ho Jeon ${ }^{1 \wedge}$ \\ ${ }^{1}$ Department of Internal Medicine, National Health Insurance Service Ilsan Hospital, Goyang, Korea; ${ }^{2}$ Department of Psychiatry, Yongin Severance \\ Hospital, Yonsei University College of Medicine, Yongin, South Korea; ${ }^{3}$ Department of Psychiatry and Institute of Behavioral Science in Medicine, \\ Yonsei University College of Medicine, Seoul, Korea \\ Contributions: (I) Conception and design: S Lee, HH Jeon; (II) Administrative support: HH Jeon; (III) Collection and assembly of data: M Lee, \\ K Kim, YK Lee; (IV) Data analysis and interpretation: BK Park, S Lee, HH Jeon; (V) Manuscript writing: All authors; (VI) Final approval of \\ manuscript: All authors. \\ "These authors contributed equally to this work. \\ Correspondence to: Han Ho Jeon, MD. Assistant Professor, Institute of Gastroenterology, Department of Internal Medicine, National Health Insurance \\ Service Ilsan Hospital, One hundred Ilsan-ro, Ilsan-donggu, Goyang-si 10444, Korea. Email: fortune22c@gmail.com; San Lee. Clinical Assistant \\ professor, Department of Psychiatry, Yongin Severance Hospital, Yonsei University College of Medicine, 363 Dongbaekjukjeon-daero, Giheung-gu, \\ Yongin-si, Gyunggi-do 16995, Korea. Email: thismountain@yuhs.ac.
}

Background: After endoscopic submucosal dissection of gastric neoplasms, surveillance endoscopy is required for patients with synchronous or metachronous neoplasms. We aimed to evaluate the risk factors associated with surveillance loss in patients who underwent endoscopic submucosal dissection.

Methods: Ninety-five patients treated with endoscopic submucosal dissection for gastric neoplasms between May 2015 and June 2016 were retrospectively reviewed. Clinicopathologic factors, sociodemographic factors, psychiatric measures, and associated risk factors for surveillance loss were evaluated. The chi-square or Fisher exact test, $t$-test, and logistic regression analysis were used in data analysis.

Results: Twenty-five (26.3\%) patients were identified as having surveillance loss. Compared to the surveillance group, the surveillance loss group was old and had dysplasia, and a healthy American Society of Anesthesiologists physical status. Similarly, surveillance loss was related to low symptom perception, low incidence of alexithymia, mindful awareness, and high trait forgiveness. Logistic regression analysis showed that dysplasia (odds ratio, 15.23; 95\% CI, 1.56-149.09, P=0.019), old age (odds ratio, 7.14; 95\% CI, 1.90-26.88, $\mathrm{P}=0.004$ ), and American Society of Anesthesiologists physical status 1 (odds ratio, 3.99; 95\% CI, 1.09-14.60, $\mathrm{P}=0.037$ ) were associated with surveillance loss.

Conclusions: Dysplasia, old age, and the American Society of Anesthesiologists physical status 1 were associated with surveillance loss in patients who underwent gastric endoscopic submucosal dissection. It could be helpful to proactively monitor patients with such conditions after gastric endoscopic submucosal dissection.

Keywords: Gastric neoplasm; endoscopic resection; surveillance

Submitted Feb 24, 2021. Accepted for publication May 30, 2021.

doi: $10.21037 /$ atm-21-891

View this article at: https://dx.doi.org/10.21037/atm-21-891

\footnotetext{
^ ORCID: 0000-0002-3393-3304.
} 


\section{Introduction}

Gastric cancer is the fourth most common cancer worldwide, especially in East Asian countries, including Korea (1). Due to the generalization of upper gastrointestinal endoscopy and Korean National Cancer Screening Programs for gastric cancer and an increase in public awareness of health check-ups, many people are undergoing endoscopy. This contributes significantly to the early detection of early gastric cancer (EGC), and the incidence of dysplasia is increasing. Gastric dysplasia is a progenitor lesion of gastric cancer, and diagnosis and treatment for dysplasia are important for early detection and prevention of gastric cancer (2). Endoscopic submucosal dissection (ESD) is a widely used treatment for gastric neoplasms (including gastric dysplasia or EGC) $(3,4)$. ESD is effective, safe, and less invasive for gastric neoplasms. Many patients have been monitored regularly after ESD. During the follow-up, metachronous or synchronous neoplasm (MSN) is discovered at higher rates in patients who have undergone ESD than in those who have undergone surgery (5-7). Previous studies found that the incidence of synchronous and metachronous lesion recurrence after ESD for gastric neoplasms vary from $12.1 \%$ to $27.9 \%$ and from $3.6 \%$ to $16 \%$, respectively $(5,6,8-11)$. Therefore, regular surveillance with endoscopy is important for the early detection of MSN recurrence after ESD. Some studies have reported endoscopic surveillance strategies; however, methods and protocols for endoscopic surveillance have not been established after ESD for gastric neoplasms.

To the best of our knowledge, no studies have investigated the risk factors for loss to follow-up in surveillance endoscopy after ESD. Therefore, this study aimed to retrospectively evaluate the characteristics and risk factors associated with surveillance endoscopy loss in patients who underwent ESD. We present the following article in accordance with the STROBE reporting checklist (available at https://dx.doi.org/10.21037/atm-21-891).

\section{Methods}

\section{Study design and population}

Patients with gastric neoplasm (including EGC or dysplasia) who underwent ESD at the National Health Insurance Service Ilsan Hospital in Korea between May 2015 and June 2016 were evaluated retrospectively. We retrospectively evaluated the prospectively collected ESD results from the endoscopic database system. During this period, we conducted a prospective study of associated risk factors for distress in patients undergoing gastric ESD (12). Therefore, we similarly collected data of various psychiatric measures that can affect individual behavior retrospectively. After ESD, we collected only the data of patients who consented to follow-up in our hospital. Patients with cognitive impairment or neurological diseases, those who underwent subtotal gastrectomy, those with more than one gastric lesion, and those who needed a second ESD were excluded. The study was conducted in accordance with the Declaration of Helsinki (as revised in 2013). The study was approved by the Institutional Review Board of National Health Insurance Service Ilsan Hospital (number: 2020-03014) and individual consent for this retrospective analysis was waived.

\section{Endoscopic submucosal dissection}

The ESD procedures in our institution has been described in detail in a previous study (13). Briefly, ESD consists of three steps as follows: (I) injecting fluid into the submucosal layer around the lesion; (II) circumferential cutting of the mucosa at the marks surrounding the lesion; and (III) submucosal dissection of the tissue under the lesion with an electrosurgical knife. A single endoscopist (HHJ) performed all the ESD procedures. Therefore, the details of ESD (prognosis and surveillance endoscopy schedule) were explained to the patients by the same clinician. In this study, we investigated Helicobacter pylori (H. pylori) infection by Gimesa staining of biopsy specimens of the antrum and body and rapid urease test $\left(\mathrm{CLO}^{\circledR}\right.$ test; Delta West, Bently, Australia) and administered eradication treatment for all patients with $H$. pylori infection after ESD.

\section{Follow-up after ESD}

The first surveillance endoscopy was performed within two to three months after ESD to assess the healing of post-ESD-induced artificial ulcers and the presence of any residual tumor. In patients with dysplasia, we recommend that a follow-up endoscopy be performed annually to detect metachronous lesions; additionally, in patients with EGC, we recommend that follow-up be performed every six months for five years to detect MSN. Generally, we emphasize that patients should at least undergo the Korean National Cancer Screening Programs for gastric cancer using upper endoscopy, which is performed every two years. All patients 
were followed up for four years from the date of ESD

\section{Data assessment}

The patients were admitted the day before the ESD procedure. Baseline characteristics, including sociodemographic factors, were collected for each patient on the day before ESD. The socioeconomic status was assessed by self-classification into one of the three predefined socioeconomic status categories presented by the levels of three domains including income, education, and occupation $(14,15)$. Self-report scales, including the European Organization for Research and Treatment of Cancer Core QOL Questionnaire 30 (EORTC QLQ-C30), the Korean version of the 20 item Toronto Alexithymia Scale (TAS-20K), Trait Forgivingness Scale-Korean (TFS-K), and Korean version of the Mindful Attention Awareness Scale (K-MAAS) were similarly administered on the day before ESD.

\section{Psychiatric measures}

Four self-report scales (EORTC QLQ-C30, TAS-20K, TFS-K, and K-MAAS) were used in this study. The $\mathrm{K}$-MAAS is a 15 -item scale designed to assess a core characteristic of mindfulness, which is a receptive state of mind in which attention, informed by a sensitive awareness of what is occurring in the present, simply observes what is happening (16). The EORTC QLQ-C30 was developed by the European Organization for Research and Treatment of Cancer Core QOL researchers in 1986 and is widely used in international clinical research on health-related quality of life in patients with cancer (17). It consists of 30 questions, including five functional scales (physical, social, role, cognitive, and emotional function), eight symptom scales (fatigue, nausea/vomiting, pain, dyspnea, sleep disturbances, appetite loss, constipation, and diarrhea), financial impact, and overall health status. We specifically used the symptom scale items in the scale because we thought that the degree of symptoms felt by the patient could play an important role in the maintenance of follow-up. The TAS-20K consists of three subscales as follow: Difficulty Identifying Feelings, Difficulty Describing Feelings, and Externally Oriented Thinking (18). The validity and reliability studies revealed that the cut-off point indicating alexithymia was 61 . The TFS-K is a measure that reflects the tendency toward forgiveness; among the five factors of personality characteristics, it reflects a positive correlation with agreeableness, conscientiousness, extroversion, and openness, and a negative correlation with neuroticism (19).

\section{Definitions}

En bloc resection was defined as the resection of the neoplasm without a residual neoplasm on endoscopy. Complete resection was defined as the resection of the neoplasm that yielded histologically confirmed tumorfree lateral and vertical margins. The follow-up period was defined from the date of the initial ESD to the date of the last upper endoscopy examination. There is no established consensus on effective surveillance strategies after ESD. Previous studies reported that annual or biannual surveillance endoscopy is the appropriate interval after ESD (20,21). Therefore, in this study, surveillance loss was defined as surveillance not being performed within one year to detect synchronous lesions and subsequently not undergoing follow-up endoscopy at a two-year interval for metachronous lesions

\section{Statistical analysis}

Categorical data were analyzed using the chi-square or Fisher exact test, whereas continuous data were analyzed using the $t$-test. Logistic regression analysis was used to identify the factors associated with surveillance loss after ESD. Values of $\mathrm{P}<0.05$ were considered statistically significant, and data analysis was performed using SPSS version 23 (IBM Corp., Armonk, NY, USA).

\section{Results}

\section{Patient characteristics}

As shown in Table 1, 58 (61.1\%) patients were men, and most patients (78.9\%) reported being married. An analysis of the American Society of Anesthesiologists (ASA) physical status showed that $73(76.9 \%)$ patients were classified into group 1 or 2 , and 11 patients $(11.6 \%)$ had psychiatric comorbidities. The gastric epithelial neoplasm lesion was located at the antrum in 59 cases $(62.1 \%)$, and the size of most lesions (76.8\%) was 10-20 mm. Fifty-seven patients $(60 \%)$ were diagnosed with low grade dysplasia, 10 patients $(10.5 \%)$ were diagnosed with high grade dysplasia, and 28 patients (29.5\%) were diagnosed with EGC. The rates of en bloc resection and complete resection were both 97.9\% (93/95). The mean scores of the EORTC QLQ-C30 
Table 1 Patient baseline characteristics

\begin{tabular}{|c|c|}
\hline Characteristic & Total $(n=95)$ \\
\hline Age (y) & $64.87 \pm 9.49$ \\
\hline \multicolumn{2}{|l|}{ Sex } \\
\hline Male & $58(61.1)$ \\
\hline Female & $37(38.9)$ \\
\hline \multicolumn{2}{|l|}{ Marriage status } \\
\hline Married & $75(78.9)$ \\
\hline Unmarried (single, divorced, widowed) & $20(21.1)$ \\
\hline \multicolumn{2}{|l|}{ Education (y) } \\
\hline$<7$ & $20(21.1)$ \\
\hline $7-12$ & $62(65.2)$ \\
\hline$>12$ & $13(13.7)$ \\
\hline \multicolumn{2}{|l|}{ Socioeconomic status } \\
\hline Low & $13(13.7)$ \\
\hline Middle & $65(68.4)$ \\
\hline High & $17(17.9)$ \\
\hline \multicolumn{2}{|l|}{ ASA physical status } \\
\hline 1 & $20(21.1)$ \\
\hline 2 & $53(55.8)$ \\
\hline 3 & $22(23.1)$ \\
\hline Psychiatric comorbidities $^{a}$ & $11(11.6)$ \\
\hline \multicolumn{2}{|l|}{ Substance use } \\
\hline Alcohol & 37 (38.9) \\
\hline Smoking & $16(16.8)$ \\
\hline \multicolumn{2}{|l|}{ Lesion location } \\
\hline Lower & $76(80.0)$ \\
\hline Middle & $11(11.6)$ \\
\hline Upper & $8(8.4)$ \\
\hline \multicolumn{2}{|l|}{ Lesion size $(\mathrm{mm})$} \\
\hline$<10$ & $13(13.7)$ \\
\hline $10-20$ & $73(76.8)$ \\
\hline$>20$ & $9(9.5)$ \\
\hline \multicolumn{2}{|l|}{ Histopathology } \\
\hline Low grade dysplasia & $57(60.0)$ \\
\hline High grade dysplasia & $10(10.5)$ \\
\hline Early gastric cancer & $28(29.5)$ \\
\hline
\end{tabular}

Table 1 (continued)
Table 1 (continued)

\begin{tabular}{lc}
\hline Characteristic & Total $(\mathrm{n}=95)$ \\
\hline En bloc resection & $93(97.9)$ \\
Complete resection & $93(97.9)$ \\
EORTC QLQ-C30 symptom score & $18.14 \pm 12.83$ \\
TAS-20K score & $50.21 \pm 9.62$ \\
TFS-K score & $34.46 \pm 4.91$ \\
K-MASS score & $36.36 \pm 11.47$ \\
\hline
\end{tabular}

Values are expressed as mean \pm SD or $n(\%)$. ${ }^{\text {aP }}$ sychiatric comorbidity included depression, panic disorder, and sleep disorder. SD, standard deviation; ASA, American Society of Anesthesiologists; EORTC QLQ-C30, European Organization for Research and Treatment of Cancer Core QOL Questionnaire 30; TAS-20K, Korean version of the 20 item Toronto Alexithymia Scale; TFS-K, Trait Forgivingness Scale-Korean; K-MASS, Korean version of the Mindful Attention Awareness Scale.

symptom scale, TAS-20K, TFS-K, and K-MASS were $18.14,50.21,34.46$, and 36.36, respectively. Detailed data are shown in Table 1.

\section{Comparison between the surveillance and surveillance loss groups}

Table 2 compares sociodemographic and clinical factors between patients in the surveillance and the surveillance loss groups. Among the 95 patients, 25 (26.3\%) were identified as having surveillance loss. No differences in sex, marital status, education level, or socioeconomic status were observed between the surveillance and surveillance loss groups. Similarly, the groups did not differ in psychiatric comorbidity, alcohol and smoking histories, lesion location, and lesion size. The surveillance loss group had a higher proportion of older patients ( $\geq 75$ years) and patients with an ASA physical status of one than the surveillance group $(\mathrm{P}=0.007$ and $\mathrm{P}=0.033$, respectively). Additionally, the surveillance group had a higher proportion of patients with EGC than the surveillance loss group $(\mathrm{P}=0.001)$. The EORTC QLQ-C30 symptom scores differed significantly between the groups, with higher symptom scores in the surveillance group than in the surveillance loss group $(\mathrm{P}=0.032)$. The TAS-20K revealed that the surveillance group had a higher incidence of alexithymia than the surveillance group $(\mathrm{P}=0.027)$. The surveillance loss group showed higher TFS-K scores than the surveillance group 
Table 2 Comparison between the surveillance and surveillance loss groups

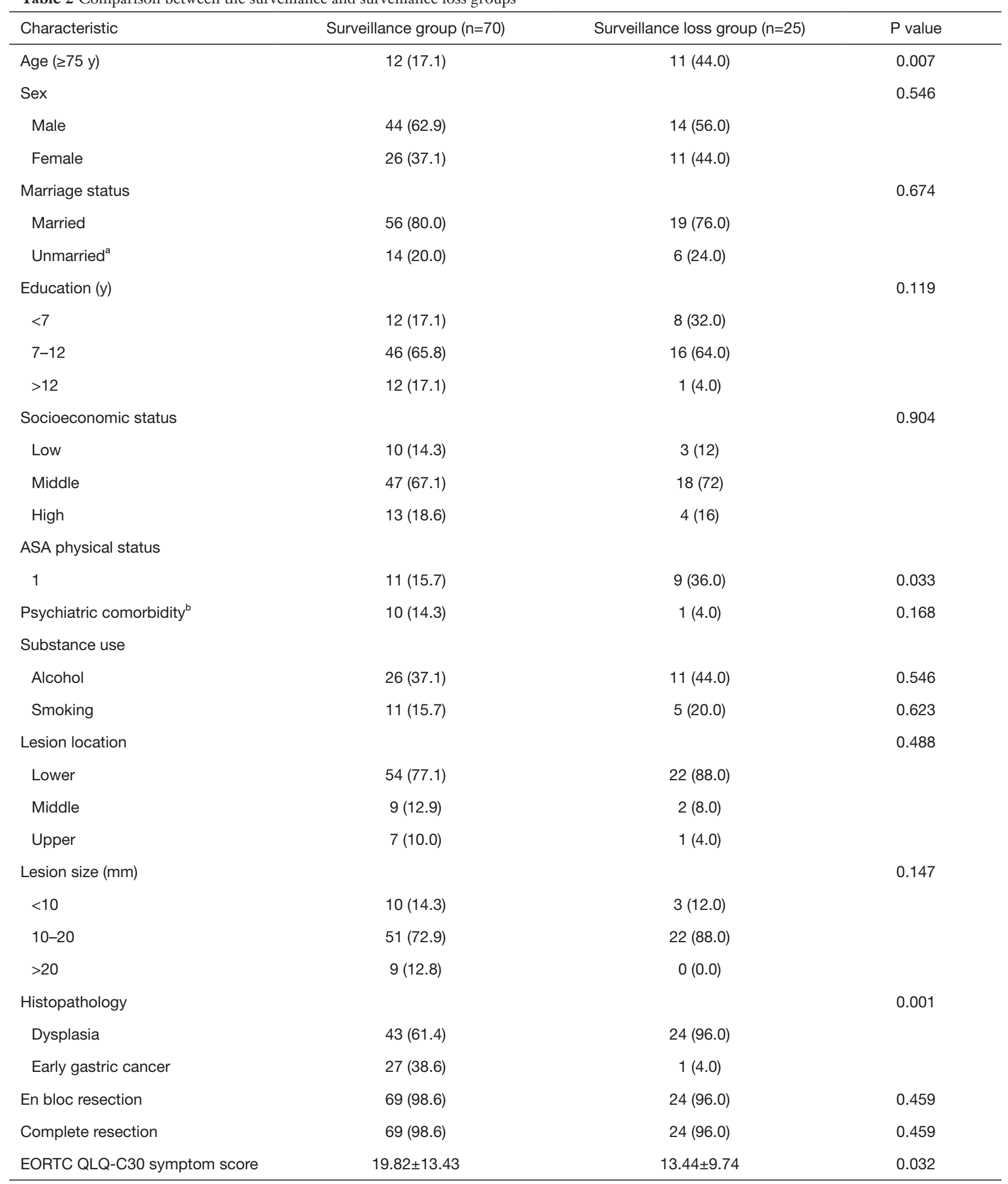

Table 2 (continued) 
Table 2 (continued)

\begin{tabular}{lccc}
\hline Characteristic & Surveillance group $(\mathrm{n}=70)$ & Surveillance loss group $(\mathrm{n}=25)$ & $\mathrm{P}$ value \\
\hline TAS-K20 (score $\geq 61)$ & $12(17.1)$ & $0(0.0)$ & 0.027 \\
TFS-K score & $33.83 \pm 4.85$ & $36.24 \pm 4.7$ & 0.034 \\
K-MAAS score & $37.97 \pm 11.45$ & $31.84 \pm 10.46$ & 0.021 \\
\hline
\end{tabular}

Values are expressed as mean \pm SD or $\mathrm{n}(\%)$. ${ }^{\mathrm{a} U n m a r r i e d}$ includes single, divorced, and widowed status. ${ }^{\mathrm{b}}$ Psychiatric comorbidity included depression, panic disorder, and sleep disorder. SD, standard deviation; ASA, American Society of Anesthesiologists; EORTC QLQ-C30, European Organization for Research and Treatment of Cancer Core QOL Questionnaire 30; TAS-20K, Korean version of the 20 item Toronto Alexithymia Scale; TFS-K, Trait Forgivingness Scale-Korean; K-MASS, Korean version of the Mindful Attention Awareness Scale.

Table 3 Univariable and multivariable logistic regression analyses of surveillance loss

\begin{tabular}{|c|c|c|c|c|}
\hline Characteristic & \multicolumn{2}{|c|}{ Univariable analysis } & \multicolumn{2}{|c|}{ Multivariable analysis } \\
\hline Dysplasia & $15.07(1.93-117.94)$ & 0.010 & $15.23(1.56-149.09)$ & 0.019 \\
\hline Age $(\geq 75 y)$ & $3.80(1.40-10.37)$ & 0.009 & 7.14 (1.90-26.88) & 0.004 \\
\hline ASA physical status 1 & $3.02(1.07-8.53)$ & 0.037 & $3.99(1.09-14.60)$ & 0.037 \\
\hline TFS-K score & $1.11(1.01-1.22)$ & 0.038 & & \\
\hline K-MAAS score & 0.95 (0.91-0.99) & 0.024 & & . \\
\hline
\end{tabular}

OR, odds ratio; Cl, confidence interval; ASA, American Society of Anesthesiologists; EORTC QLQ-C30, European Organization for Research and Treatment of Cancer Core QOL Questionnaire 30; TFS-K, Trait Forgivingness Scale-Korean; K-MASS, Korean version of the Mindful Attention Awareness Scale.

( $\mathrm{P}=0.034)$; in contrast, the surveillance group showed higher K-MASS scores than the surveillance loss group $(\mathrm{P}=0.021)$.

\section{Risk factors related to surveillance loss}

Logistic regression analysis was performed to identify the risk factors for surveillance loss (Table 3). Univariable logistic regression analysis revealed that gastric dysplasia, old age ( $\geq 75$ years), ASA physical status 1 , quality of life (EORTC QLQ-C30 symptom scale), alexithymia (TAS20K), and mindful awareness (K-MAAS) were associated with surveillance loss. Additionally, multivariable logistic regression analysis showed that dysplasia [odds ratio (OR), 15.23; 95\% CI, 1.56-149.09, $\mathrm{P}=0.019)$, old age ( $\geq 75$ years) (OR, 7.14; 95\% CI, 1.90-26.88, $\mathrm{P}=0.004)$, and ASA physical status $1(\mathrm{OR}, 3.99$; 95\% CI, 1.09-14.60, $\mathrm{P}=0.037)$ were risk factors related to surveillance loss.

\section{Discussion}

ESD is an advanced endoscopic technique that is widely accepted as a standard treatment for selected cases of gastric neoplasms $(3,4)$. In addition, ESD, compared with surgical resection, allows preservation of the stomach and helps maintain a better quality of life (22). However, ESD has a higher risk of MSN in the remnant stomach than surgical resection $(5,8,11)$. Therefore, regular surveillance is required for the early detection of lesion recurrence, and it is important to identify risk factors related to surveillance loss after ESD.

We evaluated differences in psychiatric status between the surveillance and surveillance loss groups. The EORTC QLQ-C30 symptom scale, TAS-20K, TFS-K, and K-MAAS scores were significantly different between the groups. The EORTC QLQ-C30 symptom scale measures the severity of 
symptoms, such as fatigue, pain, nausea, and vomiting, over the past week (17). The higher the score, the more severe the related symptoms, and patients in the surveillance group may have experienced more symptoms and undergone more follow-ups with awareness than those in the surveillance loss group. The TAS-20K is a measure of the level of alexithymia. A score of 61 or higher indicates alexithymia, a score of 52-60 indicates a borderline state, and a score of 51 or less indicates the absence of alexithymia (18). Alexithymia was more frequently observed in the surveillance group than in the surveillance loss group in this study. Alexithymia has been reported to be related to high anxiety, and high anxiety about one's health status may lead to continued surveillance (23-25). The TFS-K is a measure that reflects trait forgiveness, which means the tendency to forgive, and trait forgiveness has been reported to be negatively correlated with neuroticism-related anxiety (19). In this study, the TFS-K score was significantly lower in the surveillance group than in the surveillance loss group, which may also indirectly indicate the possibility of continuing follow-up due to the high anxiety for disease recurrence. The K-MAAS is a measure for evaluating attention and awareness, the major elements of mindfulness (16). According to Bishop et al., mindfulness is a form of awareness, and it is characterized by "self-regulation of attention that enables awareness of the present moment experience" (26). The K-MAAS score of the surveillance group was significantly higher than that of the surveillance loss group. This is because the current attention and awareness of symptoms of patients in the surveillance groups were relatively high compared to those in the surveillance loss group. Therefore, they probably perceived their symptoms more frequently and continued follow-up.

Logistic regression analysis showed that the risk factors for surveillance loss after ESD were dysplasia, old age ( $\geq 75$ years), and normal health (ASA physical status of one) without psychiatric factors. The reason for this finding is unclear. Patients may often underestimate the importance of surveillance endoscopy due to the misconception that gastric neoplasm slowly develops in older patients, leading to a false sense of relief that dysplasia is less invasive than EGC. Patients may not have been followed up with surveillance because they were healthy and experienced no specific symptoms after ESD. It is crucial to consider the risk of MSN in the remnant stomach and the importance of surveillance.

The clinical significance of this study is as follows: First, the risk factors for surveillance loss were analyzed, including sociodemographic, psychiatric, and clinicopathological factors. This is because patients are affected by various factors when considering to undergo surveillance endoscopy. Second, when gastric dysplasia is diagnosed, there is a high possibility that synchronous dysplasia or gastric cancer is present $(11,27,28)$, and it is highly likely to develop metachronous dysplasia or gastric cancer $(10,11,28,29)$. Yoon et al. showed that the incidence of gastric cancer after endoscopic resection for gastric dysplasia was similar to that of EGC (10). There are several previous studies on the risk factors for recurrence after endoscopic resection. These studies reported that recurrence was more frequent in patients with multiple synchronous lesions, old age, intestinal metaplasia, and undifferentiated histology of EGC (11,30-32). In other words, older age is a risk factor for recurrence after endoscopic resection and surveillance loss after endoscopic resection. The elderly population is growing with an increased incidence of gastric neoplasm, and, in a previous study, the incidence of metachronous recurrence generally increased steadily over five years and plateaued at 10 years (20). In elderly patients, ESD is an effective and safe therapy compared to surgery due to comorbidity $(33,34)$. The longterm outcome of ESD for elderly patients is favorable, and this outcome is not significantly different from those in younger patients (35). Therefore, even if elderly patients with gastric neoplasm are healthy, surveillance endoscopy is necessary after the initial ESD.

Our study has several limitations. First, there is a risk of selection bias due to the retrospective and singlecenter study design. However, the risk may have been reduced because prospectively collected data were used. Second, the sample size was not sufficient to generalize our results. Third, surveillance was explained using the same explanatory materials after ESD, and only one endoscopist was responsible for explaining surveillance in our study. How the disease and surveillance strategies were explained to the patient may have affected the patients' decision to undergo surveillance endoscopy after ESD. Hence, multicenter prospective studies should be performed to evaluate the risk factors for surveillance.

In conclusion, this study revealed that older age, normal health, and gastric dysplasia were associated with greater loss to follow-up in patients undergoing gastric ESD. It could be helpful to screen and further proactively monitor patients after performing gastric ESD, which may improve surveillance after ESD. 


\section{Acknowledgments}

Funding: This study was supported by a grant from the National Health Insurance Service Ilsan Hospital, Republic of Korea.

\section{Footnote}

Reporting Checklist: The authors have completed the STROBE reporting checklist. Available at https://dx.doi. org/10.21037/atm-21-891

Data Sharing Statement: Available at https://dx.doi. org/10.21037/atm-21-891

Conflicts of Interest: All authors have completed the ICMJE uniform disclosure form (available at https://dx.doi. org/10.21037/atm-21-891). The authors have no conflicts of interest to declare.

Ethical Statement: The authors are accountable for all aspects of the work in ensuring that questions related to the accuracy or integrity of any part of the work are appropriately investigated and resolved. The study was conducted in accordance with the Declaration of Helsinki (as revised in 2013). The study was approved by the Institutional Review Board of National Health Insurance Service Ilsan Hospital (number: 2020-03-014) and individual consent for this retrospective analysis was waived.

Open Access Statement: This is an Open Access article distributed in accordance with the Creative Commons Attribution-NonCommercial-NoDerivs 4.0 International License (CC BY-NC-ND 4.0), which permits the noncommercial replication and distribution of the article with the strict proviso that no changes or edits are made and the original work is properly cited (including links to both the formal publication through the relevant DOI and the license). See: https://creativecommons.org/licenses/by-nc-nd/4.0/.

\section{References}

1. Kamangar F, Dores GM, Anderson WF, et al. Patterns of cancer incidence, mortality, and prevalence across five continents: defining priorities to reduce cancer disparities in different geographic regions of the world. J Clin Oncol 2006;24:2137-50.

2. Lauwers GY, Riddell RH. Gastric epithelial dysplasia. Gut
1999;45:784-90.

3. Gotoda T, Iwasaki M, Kusano C, et al. Endoscopic resection of early gastric cancer treated by guideline and expanded National Cancer Centre criteria. Br J Surg 2010;97:868-71.

4. Chung IK, Lee JH, Lee SH, et al. Therapeutic outcomes in 1000 cases of endoscopic submucosal dissection for early gastric neoplasms: Korean ESD Study Group multicenter study. Gastrointest Endosc 2009;69:1228-35.

5. Ryu SJ, Kim BW, Kim BG, et al. Endoscopic submucosal dissection versus surgical resection for early gastric cancer: a retrospective multicenter study on immediate and longterm outcome over 5 years. Surg Endosc 2016;30:5283-9.

6. Pyo JH, Lee H, Min BH, et al. Long-Term Outcome of Endoscopic Resection vs. Surgery for Early Gastric Cancer: A Non-inferiority-Matched Cohort Study. Am J Gastroenterol 2016;111:240-9.

7. Cho JH, Cha SW, Kim HG, et al. Long-term outcomes of endoscopic submucosal dissection for early gastric cancer: a comparison study to surgery using propensity scorematched analysis. Surg Endosc 2016;30:3762-73.

8. Ami R, Hatta W, Iijima K, et al. Factors Associated With Metachronous Gastric Cancer Development After Endoscopic Submucosal Dissection for Early Gastric Cancer. J Clin Gastroenterol 2017;51:494-9.

9. Kato M, Nishida T, Yamamoto K, et al. Scheduled endoscopic surveillance controls secondary cancer after curative endoscopic resection for early gastric cancer: a multicentre retrospective cohort study by Osaka University ESD study group. Gut 2013;62:1425-32.

10. Yoon SB, Park JM, Lim CH, et al. Incidence of gastric cancer after endoscopic resection of gastric adenoma. Gastrointest Endosc 2016;83:1176-83.

11. Jang MY, Cho JW, Oh WG, et al. Clinicopathological characteristics of synchronous and metachronous gastric neoplasms after endoscopic submucosal dissection. Korean J Intern Med 2013;28:687-93.

12. Lee S, Oh ST, Lee H, et al. Associated risk factors for psychological distress in patients with gastric epithelial neoplasm undergoing endoscopic submucosal dissection. Medicine (Baltimore) 2018;97:e13912.

13. Cho YS, Shin SY, Hwang C, et al. Safety and Effectiveness of Endoscopist-Directed Nurse-Administered Sedation during Gastric Endoscopic Submucosal Dissection. Gastroenterol Res Pract 2017;2017:4723626.

14. Farkas J, Pahor M, Zaletel-Kragelj L, et al. Self-rated health in different social classes of Slovenian adult population: nationwide cross-sectional study. Int J Public 
Health 2011;56:45-54.

15. Giatti L, Camelo Ldo V, Rodrigues JF, et al. Reliability of the MacArthur scale of subjective social status - Brazilian Longitudinal Study of Adult Health (ELSA-Brasil). BMC Public Health 2012;12:1096.

16. Brown KW, Ryan RM The benefits of being present: mindfulness and its role in psychological well-being. J Pers Soc Psychol 2003;84:822-48.

17. Yun YH, Park YS, Lee ES. Validation of the Korean version of the EORTC QLQ-C30. Qual Life Res 2004;13:863-8.

18. Bagby RM, Parker JD, Taylor GJ, et al. The twentyitem Toronto Alexithymia Scale--I. Item selection and cross-validation of the factor structure. J Psychosom Res 1994;38:23-32.

19. Berry JW, Worthington EL Jr, O'Connor LE, et al. Forgivingness, vengeful rumination, and affective traits. J Pers 2005;73:183-225.

20. Nakajima T, Oda I, Gotoda T, et al. Metachronous gastric cancers after endoscopic resection: how effective is annual endoscopic surveillance? Gastric Cancer 2006;9:93-8.

21. Min BH, Kim ER, Kim KM, et al. Surveillance strategy based on the incidence and patterns of recurrence after curative endoscopic submucosal dissection for early gastric cancer. Endoscopy 2015;47:784-93.

22. Choi JH, Kim ES, Lee YJ, et al. Comparison of quality of life and worry of cancer recurrence between endoscopic and surgical treatment for early gastric cancer. Gastrointest Endosc 2015;82:299-307.

23. Karukivi M, Hautala L, Kaleva O, et al. Alexithymia is associated with anxiety among adolescents. J Affect Disord 2010;125:383-7.

24. Espina Eizaguirre A, Ortego Saenz de Cabezón A, Ochoa de Alda I, et al. Alexithymia and its relationships with anxiety and depression in eating disorders. Pers Individ Dif 2004;36:321-31.

25. Mantani T, Saeki T, Inoue S, et al. Factors related to anxiety and depression in women with breast cancer and their husbands: role of alexithymia and family functioning. Support Care Cancer 2007;15:859-68.

Cite this article as: Lee M, Kim K, Lee YK, Park BK, Lee S, Jeon HH. Risk factors associated with surveillance loss after endoscopic submucosal dissection in patients with gastric neoplasm. Ann Transl Med 2021;9(14):1127. doi: 10.21037/atm21-891
26. Bishop SR, Lau M, Shapiro S, et al. Mindfulness: A Proposed Operational Definition. Clin Psychol 2004;11:230-41.

27. Kim HH, Kim JH, Kim GH, et al. Causes of missed synchronous gastric epithelial neoplasms with endoscopic submucosal dissection: a multicenter study. Scand J Gastroenterol 2013;48:1339-46.

28. Baek DH, Kim GH, Park DY, et al. Gastric epithelial dysplasia: characteristics and long-term follow-up results after endoscopic resection according to morphological categorization. BMC Gastroenterol 2015;15:17.

29. Cho CJ, Ahn JY, Jung HY, et al. The incidence and locational predilection of metachronous tumors after endoscopic resection of high-grade dysplasia and early gastric cancer. Surg Endosc 2017;31:389-97.

30. Arima N, Adachi K, Katsube T, et al. Predictive factors for metachronous recurrence of early gastric cancer after endoscopic treatment. J Clin Gastroenterol 1999;29:44-7.

31. Han JS, Jang JS, Choi SR, et al. A study of metachronous cancer after endoscopic resection of early gastric cancer. Scand J Gastroenterol 2011;46:1099-104.

32. Seo JH, Park JC, Kim YJ, et al. Undifferentiated histology after endoscopic resection may predict synchronous and metachronous occurrence of early gastric cancer. Digestion 2010;81:35-42.

33. Chiu PW, Teoh AY, To KF, et al. Endoscopic submucosal dissection (ESD) compared with gastrectomy for treatment of early gastric neoplasia: a retrospective cohort study. Surg Endosc 2012;26:3584-91.

34. Park CH, Lee H, Kim DW, et al. Clinical safety of endoscopic submucosal dissection compared with surgery in elderly patients with early gastric cancer: a propensitymatched analysis. Gastrointest Endosc 2014;80:599-609.

35. Komori K, Nakamura K, Ihara E, et al. Endoscopic Submucosal Dissection is Feasible for Very Elderly Patients with Early Gastric Cancer : Comparison of Short-Term and Long-Term Outcomes in Very Elderly and Non-Elderly Patients. Fukuoka Igaku Zasshi 2016;107:72-81. 